Thierry Troosters ${ }^{1}$, Nathalie Tabin ${ }^{2}$, Daniel Langer ${ }^{1}$, Chris Burtin $^{3}$, Michelle Chatwin ${ }^{4}$, Enrico M. Clini ${ }^{5}$, Margareta Emtner6, Rik Gosselink ${ }^{1}$, Kathleen Grant ${ }^{7}$, Deniz Inal-Ince ${ }^{8}$, Agnieszka Lewko9, Eleanor Main ${ }^{10}$, Sharon Mitchell ${ }^{11}$, Alexandra Niculescu ${ }^{12}$, Beatrice Oberwaldner ${ }^{13}$, Fabio Pitta ${ }^{14}$

thierry.troosters@kuleuven.be

@ERStalk

\title{
Review
}

\section{Introduction of the harmonised respiratory physiotherapy curriculum}

Cite as: Troosters T, Tabin N, Langer D, et al. Introduction of the harmonised respiratory physiotherapy curriculum. Breathe 2019; 15: 110-115.
Building on the core syllabus for postgraduate training in respiratory physiotherapy, published in 2014, the European Respiratory Society (ERS) respiratory physiotherapy task force has developed a harmonised and structured postgraduate curriculum for respiratory physiotherapy training. The curriculum outlines the knowledge, skills and attitudes which must be mastered by a respiratory physiotherapist working with adult or paediatric patients, together with guidance for minimal clinical exposures, and forms of learning and assessment.

This article presents the rationale, methodology and content of the ERS respiratory physiotherapy curriculum. The full curriculum can be found in the supplementary material.

\section{Introduction}

Harmonising education is one of the most challenging aspects of ensuring mobility of healthcare professionals across countries and regions of the world. While patients are affected by the same respiratory conditions, the healthcare systems in which patients are treated differ markedly, and likewise the training of healthcare providers within these systems. This is particularly true for physiotherapy where the educational training varies from a short professional bachelor's degree to an academic Master of Science. In one country several educational systems may coexist [1]. Respiratory physiotherapy is considered a subspecialty of physiotherapy in several countries. Dedicated training tracks for respiratory physiotherapists exist worldwide, and dedicated professional organisations assemble (cardio-) respiratory physiotherapists. In the European Respiratory Society (ERS), respiratory physiotherapists find a place in group 9.2 of the Allied Health Professionals Assembly. While in our initial survey we identified several programmes that covered respiratory physical therapy to some (variable) extent, none of the graduate training programmes comprehensively covered the wide spectrum of respiratory physiotherapy offerings [2].

The Harmonised Education and Training in Respiratory Medicine for European specialists (HERMES) was launched in 2005 to address this challenge. A strong curriculum design methodology was established from this past initiative and has been used across ERS educational projects, disease areas and professional groups. In 2014, the respiratory physiotherapy task force published a core syllabus for postgraduate training in respiratory physiotherapy, as part of the former HERMES initiative [3].

Moving forward, the task force strived to develop a harmonised and structured postgraduate curriculum

\section{CrossMark}

C)ERS 2019
@ERSpublications

The respiratory physiotherapy curriculum describes the knowledge, skills and attitudes that must be mastered by a respiratory physiotherapist working with adults and/or children. http://bit.ly/2Do7VII 
for respiratory physiotherapy training. It is useful here to distinguish the difference between a syllabus, identifying a list of the knowledge and skills required of a respiratory physiotherapist, and a curriculum identifying three core strands of how to acquire these skills through prescribed learning outcomes and assessment criteria, as well as suggestions on the learning resources required. This curriculum defines the standards for training and constitutes a framework which physiotherapy education leaders could make use of, in the evaluation of their own activities and organisations. The ultimate aim is the enhancement of patient healthcare in a wellrecognised specialty of physiotherapy. Previously consensus documents have proposed minimal requirements for physiotherapy in specific settings, relevant to respiratory physiotherapists, for example in intensive care [4-6]. The present curriculum attempts to cover the wide range of patients, pathologies and settings a respiratory physiotherapist can be working in. This article presents the rationale, methodology and content of the ERS respiratory physiotherapy curriculum.

\section{Rationale}

The ERS respiratory physiotherapy curriculum was based on the published syllabus and sought to develop respiratory physiotherapy standards for postgraduate training that are clearly defined, meaningful, appropriate, relevant, measurable, achievable and adoptable by users [7]. The aim was to create a curriculum that would be flexible enough to allow training centres to use a variety of methods to reach the same outcomes. Some flexibility was necessary to define a training framework that would remain manageable, attainable and realistic. Hence, a modular training approach was chosen such that all or only some of the modules could be adopted in different countries/regions, under different healthcare systems. As "accreditation" for respiratory physiotherapy is largely absent in Europe, the modular approach also allows individual physiotherapists with an interest in respiratory physiotherapy to gradually build-up knowledge, skills and attitudes in an increasing number of modules, according to their professional needs. A review of the curriculum will be planned in 10 years to maintain those standards in training.

\section{Curriculum development methodology}

The situational analysis and needs assessment were performed in 2013 as the first steps of curriculum design [1]. Training and assessment practice differences in respiratory physiotherapy across Europe were identified. Within the statement of intent, the target audience, goals and outcomes were outlined, laying the foundation for the project.
After reaching consensus on the overall objectives and on which topics should be included in the syllabus [2], the task force continued with the programme development, moving to the curriculum phase. Prideaux [8] defines the curriculum as the "expression of educational ideas in practice". It sets up the plan of how the goals will be achieved.

The curriculum expands on the syllabus content, which is a list of topics, and for each item specifies the following.

- Learning outcomes that a respiratory physiotherapist should possess, defined over three domains: knowledge (cognitive skills), skills (psychomotor skills) and attitudes (affective skills) [9].

- Level(s) of assessment based on Miller's model of clinical competence [10], which have been assigned in alignment with the learning outcomes.

- Assessment methods that are deemed fit for purpose, which is essential to the validity of assessments and to predict whether a trainee is competent to practice.

- Teaching and learning activities, which reflect work-based learning (participation in management of patients, or implementation of a treatment plan with patient collaboration), nonwork-based learning (self-directed learning), formal learning (participation in a skills-based course or attendance at meetings for formal training in specific areas) and learning with other healthcare professionals.

- Minimum clinical exposure requirements, such as the number of patient encounters considered necessary for a respiratory physiotherapist to practice unsupervised.

\section{Process of curriculum development}

The task force comprised a chest physician, Enrico Clini (Italy), and several physiotherapists who had trained and practised in various regions across the world: Chris Burtin (Belgium), Margareta Emtner (Sweden), Rik Gosselink (the Netherlands and Belgium), Kathleen Grant (UK, Switzerland and a representative of the European Respiratory Care Association), Deniz Inal-Ince (Turkey), Agnieszka Lewko (Poland and UK), Eleanor Main (South Africa and UK), Beatrice Oberwaldner (Austria), Michelle Chatwin (UK) and Daniel Langer (Germany and Belgium). The task force was co-chaired by Fabio Pitta (Brazil) and Thierry Troosters (Belgium). Beatrice Oberwaldner, Michelle Chatwin and Eleanor Main reinforced the team for the paediatric specialty. All the task force members had extensive clinical and/or research experience and teach at an undergraduate or postgraduate level.

The prerequisites for eligibility to follow this curriculum were defined at the beginning of the 


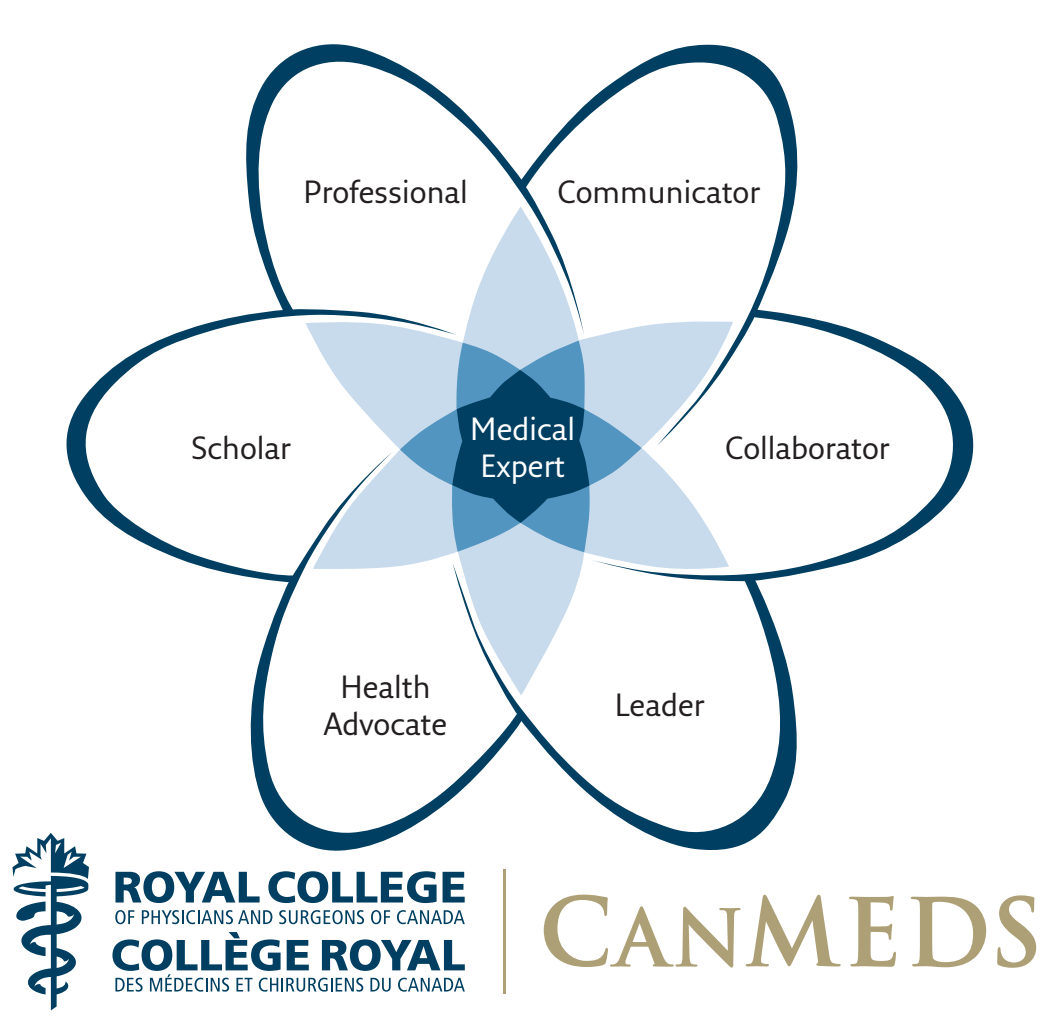

Figure 1 CanMEDS roles. Copyright (C) 2015 The Royal College of Physicians and Surgeons of Canada. http://www.royalcollege.ca/rcsite/canmeds/canmeds-framework-e. Reproduced with permission.
Attitudes were then developed according to the CanMEDS competency framework [12]. Competency-based frameworks are used in medical education to improve patient care and include competencies exceeding the sole domain of medical expertise [12]. CanMEDS comprises seven roles, displayed in figure 1. The task force considered those roles that were important for each module and added specific roles where required. The CanMEDs roles were integrated into the development of specific attitudes, especially those enabling competencies which supported the expert role within this framework. It was observed that there was a large overlap between the CanMEDS roles and the general attitudes attributed to a physiotherapist. Therefore, only those attitudes that deserve specific attention in a module were retained.

The next step was to define the teaching and learning opportunities, the assessment and minimal exposure requirements. These aspects go hand in hand with the learning outcomes. This is referred to in the literature as "constructive alignment" (summarised in figure 2) [13]. In principle, the constructive alignment aims to directly affiliate assessments and clinical exposures with the intended learning outcomes.

The teaching and learning opportunities were formulated as clear examples for each of the different types of learning environments stated below.

1) Work-based learning (participation in management of patients, or implementation of a treatment plan with patient collaboration).

2) Non-work-based learning (self-directed learning).

3) Formal learning (participation in a skills-based course or attendance at meetings for formal training in specific areas).

4) Learning with other healthcare professionals (attendance at meetings with colleagues to discuss patient treatment or care).

Each task force member received a template document after participation in a curriculum workshop. Each module was assigned to a pair of task force members. They were provided with a list of verbs to be used (according to Bloom's taxonomy of learning domains), a list of possible teaching and learning methods, information on the Miller's model of competence and a list of assessment methods. Telephone conferences including the pair of task force members and the

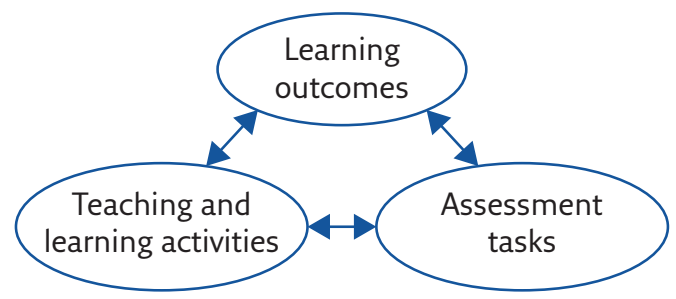

Figure 2 Constructive alignment. 


\begin{tabular}{|c|c|c|c|c|c|c|c|}
\hline \multicolumn{8}{|c|}{ Module 7 Non-invasive ventilation for the respiratory physiotherapist: Mandatory } \\
\hline $\begin{array}{l}\text { Module } \\
\text { competency }\end{array}$ & \multicolumn{7}{|c|}{ To explain the rationale and to apply appropriately the use of non-invasive ventilation (NIV) in the respiratory patient. } \\
\hline Syllabus item & Knowledge & Skills & Attitudes & $\begin{array}{l}\text { Teaching } \\
\text { and Learning } \\
\text { Opportunities }\end{array}$ & $\begin{array}{l}\text { Assessment } \\
\text { methods }\end{array}$ & $\begin{array}{c}\text { Level of } \\
\text { Assessment }\end{array}$ & $\begin{array}{l}\text { Minimum clinical } \\
\text { and educational } \\
\text { exposure }\end{array}$ \\
\hline $\begin{array}{l}\text { 1. Definition of } \\
\text { modalities and } \\
\text { parameters, } \\
\text { difference } \\
\text { between acute } \\
\text { ventilatory } \\
\text { support (NIV } \\
\text { and CPAP) and } \\
\text { long-term } \\
\text { ventilator } \\
\text { support, }\end{array}$ & $\begin{array}{l}\text { - Describe continuous } \\
\text { positive airway pressure } \\
\text { (CPAP) and NIV } \\
\text { - Review indications and } \\
\text { application of ventilator } \\
\text { support therapy } \\
\text { according to the current } \\
\text { guidelines in the field } \\
\text { - Summarise the } \\
\text { mechanism of action for } \\
\text { ventilator support and } \\
\text { discuss physiological } \\
\text { effects of ventilator } \\
\text { support to the patient } \\
\text { with regard to arterial } \\
\text { blood gases (ABGs), } \\
\text { work of breathing (WOB), }\end{array}$ & $\begin{array}{l}\text { - Identify the } \\
\text { correct } \\
\text { environment for } \\
\text { initiating NIV } \\
\text { depending on } \\
\text { - indication for } \\
\text { NIV } \\
\text { (prophylactic, } \\
\text { acute, chronic, } \\
\text { palliative) } \\
\text { - level of } \\
\text { dependency } \\
\text { - availability of } \\
\text { adequate } \\
\text { monitoring } \\
\text { - availability of } \\
\text { correct skill mix }\end{array}$ & $\begin{array}{l}\text { - Scholar: } \\
1.1 \text { develop, } \\
\text { implememt, } \\
\text { monitor and } \\
\text { revise a personal } \\
\text { learning plan to } \\
\text { enhance } \\
\text { professional } \\
\text { practice; } \\
1.2 \text { identify } \\
\text { opportunities for } \\
\text { learning and } \\
\text { improvement by } \\
\text { regularly } \\
\text { reflecting on and } \\
\text { assessing their } \\
\text { performance } \\
\text { using various }\end{array}$ & \begin{tabular}{|} 
Umbrella for all \\
syllabus items \\
Self directed \\
learning \\
(NIV simulation, \\
literature search with \\
appraisal of a \\
scientific article \\
related to the clinical \\
presentation of a \\
patient currently \\
being managed
\end{tabular} & $\begin{array}{c}\text { Umbrella for all } \\
\text { syllabus items } \\
\text { MCQ } \\
\text { (knowledge based } \\
\text { items) } \\
\text { NIV simulator } \\
\text { (skill based } \\
\text { assessment) } \\
\text { Portfolio } \\
\text { (knowledge and } \\
\text { skill based) }\end{array}$ & $\begin{array}{l}\text { Umbrella for } \\
\text { all syllabus items }\end{array}$ & $\begin{array}{l}\text { Elaborate } \\
\text { management plan } \\
\text { and carry out } \\
\text { treatments under } \\
\text { supervision for a } \\
\text { minimum of } \mathbf{1 0} \\
\text { patients (half of } \\
\text { them acute) and } \\
\text { when competency } \\
\text { is demonstrated, } \\
\text { manage another } \\
\mathbf{1 0} \text { unsupervised. }\end{array}$ \\
\hline
\end{tabular}

Figure 3 Example of a module section from the adult respiratory physiotherapy curriculum. The full curriculum can be found in the supplementary material.

educational specialist from the ERS were organised to come to a consensus on items and wording. The modules delivered were first reviewed by the ERS office and all modules were discussed during a plenary session to determine consensus for each module and ensure harmonisation across modules. An example of a module section is presented in figure 3 .

After finalisation of the curriculum document, the adult and paediatric paths were reviewed by the national experts and the ERS medical educational adviser, Griet Peeraer. Out of 12 national experts invited for review of the adult track, nine provided their review input including general comments and suggestions on the overall content and structure of the curriculum, specific suggestions and targeted feedback. For the paediatric review, 30 experts were invited and 12 provided their review. The reviewer pool represented the following countries: Australia, Germany, Spain, Norway, Poland, Portugal, Ireland, Switzerland, UK, Austria, Sweden, Belgium, Turkey and Italy. They held various professional positions including respiratory physiotherapist, consultant clinical research physiotherapist and associate professor cardiorespiratory physiotherapist. The feedback was broadly positive, but revealed some areas of inconsistency and repetition which were subsequently addressed.

The core curriculum documents for adult and paediatric patients can be found in the online supplementary material.

\section{Discussion}

The curriculum developed by the task force sets a high benchmark, in terms of the knowledge, skill and attitude requirements for physiotherapists that aspire to comprehensive postgraduate training in respiratory physiotherapy. In several countries dedicated physiotherapists with particular competences in respiratory physiotherapy do exist. However, the requirements to attain such a specialisation or "particular competence" largely differ. The present project provides some guidance for educational tracks as to the requirements for designated areas of respiratory physiotherapy (modules) or to claim a full specialisation in respiratory physiotherapy at a postgraduate level. Conscious of these potential expectations, the curriculum was designed in a modular format, with separate adult and paediatric paths, and additional modules for intensive care. This was done to accommodate the clinical reality, where professionals are often subspecialised and deal with specific patient populations. The decision to separate the paediatric from the adult path was debated, as the principles of competent care overlap in multiple respects. As the application of many skills is different for paediatric specialists, it was decided to keep the paths separate. The modular approach also allows for gradual and tailored learning. Since full accreditation of a "respiratory physiotherapist" (an equivalent of a specialised chest physician) is not available in most countries, the curriculum is 
mainly geared towards a continued professional development process. The modular approach was felt to be the best suited to fit this model.

Integrating attitudes while avoiding repetition was another challenge. It was decided that these were to be regrouped by module for better clarity. Attitudes specific to some items were added where required.

An additional difficulty was in deciding the minimal clinical exposure requirements. This refers to an indicative minimum number of procedures to which each trainee should be directly exposed throughout the duration of the training. To the best of the panel's knowledge, no validated benchmarks are available for the whole set of modules or even specific items. Instead, internships in physiotherapy are often benchmarked in terms of the number of general contact hours at the time of certification. Similarly, to achieve "specialisation" a time period of exposure to the relevant patient group is typically used. As the curriculum spans a broad spectrum of interventions and diagnostic techniques, it is difficult to acquire all these in a specific and reasonable time window within a particular healthcare setting. It was agreed to define a total number of patients per item or, where relevant per procedure. These numbers need further validation and are based on a consensus within the expert team and reviewers. This is considered a starting point. In addition, to identify the specific procedures that must be mastered in each module it was proposed that a certain number of cases would be necessary to be performed both independently and under supervision. This decision very much reflects best practice in medical education and minimises the differences that respiratory physiotherapists are exposed to across settings.

The ERS respiratory physiotherapy curriculum aims to cover all aspects of respiratory physiotherapy.
While the curriculum is designed for respiratory physiotherapists, it also provides a guide to other allied health professionals who may perform specific clinical activities within their competency in specific regions of Europe or beyond. This is true for exercise training, or management of patients receiving noninvasive ventilation or mechanical ventilation for example. It is therefore important to align the regional/domestic requirements, and particularly legal and reimbursement arrangements. Throughout the document, interdisciplinary collaborations were therefore highly emphasised as key for physiotherapy and patient care. Similarly, the degree of responsibility for physiotherapists differs across regions. In many countries, physiotherapists work solely under prescription from a medical doctor. However, increasingly more countries and regions also have direct access to physiotherapists with a high degree of professional autonomy. In either case the respiratory physiotherapist is embedded in a care team around the patient and effective communication with other healthcare providers as well as with the patient and family is an essential attitude.

\section{Conclusion}

The current curriculum provides a modular framework for international training in respiratory physiotherapy. It describes the knowledge, skills and attitudes which must be mastered by a respiratory physiotherapist working with adult or paediatric patients. It also provides guidance for minimal clinical exposures, forms of learning and assessment. The curriculum contains the elements around which an E-portfolio can be built, and it sets out a benchmark for endorsement of educational opportunities organised by others as well as the ERS.

\begin{abstract}
Affiliations
Thierry Troosters ${ }^{1}$, Nathalie Tabin ${ }^{2}$, Daniel Langer ${ }^{1}$, Chris Burtin ${ }^{3}$, Michelle Chatwin $^{4}$, Enrico M. Clini ${ }^{5}$, Margareta Emtner ${ }^{6}$, Rik Gosselink ${ }^{1}$, Kathleen Grant ${ }^{7}$, Deniz Inal-Ince ${ }^{8}$, Agnieszka Lewko9, Eleanor Main ${ }^{10}$, Sharon Mitchell ${ }^{11}$, Alexandra Niculescu ${ }^{12}$, Beatrice Oberwaldner ${ }^{13}$, Fabio Pitta ${ }^{14}$

${ }^{1}$ Dept of Rehabilitation Sciences, KU Leuven, Leuven, Belgium. 2Education Dept, European Respiratory Society, Lausanne, Switzerland. ${ }^{3}$ Reval Rehabilitation Research Center, BIOMED Biomedical Research Institute, Faculty of Rehabilitation, Hasselt University, Diepenbeek, Belgium. ${ }^{4}$ Academic and Clinical Dept of Sleep and Breathing, Royal Brompton and Harefield NHS Foundation Trust, London, UK. ${ }^{5}$ Dept of Medical and Surgical Sciences, University of Modena Reggio Emilia and University Hospital of Modena Policlinico, Modena, Italy. ${ }^{6}$ Depts of Neuroscience and Medical Sciences, Uppsala University, Uppsala, Sweden. ${ }^{7}$ Dept of Cardio-respiratory Physiotherapy, Vaud University Hospital, Lausanne, Switzerland. ${ }^{8}$ Dept of Physiotherapy and Rehabilitation, Faculty of Health Sciences, Hacettepe University, Ankara, Turkey. ${ }^{9}$ Dept of Rehabilitation Sciences, Faculty of Health, Social Care and Education, Kingston University and St. George's University of London, London, UK. ${ }^{10}$ Physiotherapy Dept, Great Ormond Street Institute of Child Health, University College London, London, UK. ${ }^{11}$ World Heart Federation, Geneva, Switzerland. ${ }^{12}$ Faculty of Education, Center for Educational Measurement (CEMO), University of Oslo, Oslo, Norway. ${ }^{13}$ Postgraduate School, Medical University, Graz, Austria. ${ }^{14}$ Dept of Physiotherapy, Laboratory of Research in Respiratory Physiotherapy (LFIP), State University of Londrina (UEL), Londrina, Brazil.
\end{abstract}

Supplementary material

This article has supplementary material available from breathe.ersjournals.com 


\section{Acknowledgements}

Thank you to the reviewers and medical advisor: Bronwen Connolly (Guy's and St Thomas' NHS Foundation Trust, London, UK), Rosa Josa (Fundació Escoles Universitàries Gimbernat-UAB, San Cugat del Vallès (Barcelona), Spain), Philippe Joud (Centre de kinésithérapie respiratoire, Lyon, France), Anna-Lena Lagerkvist (University of Gothenburg, Gothenburg, Sweden), Sara Lucia Menez (Augusto Motta University Centre, Rio de Janeiro, Brazil), Sara Mariani (Fondazione Ca' Granda Ospedale Maggiore Policlinico, Milan, Italy), Alda Marques (University of Aveiro, Aveiro, Portugal), Roman Nowobilski (Jagiellonian University Medical College, Cracow, Poland), Malin Nygren-Bonnier (Karolinska Institutet, Huddinge, Sweden), Ulrike Pachernigg (Universitätsklinik für Kinder- und Jugendheilkunde, Medizinische Universität Graz, Graz, Austria), Shane Patman (University of Notre Dame Australia, Fremantle, Australia), Griet Peeraer (Medical Advisor) (Universiteit Antwerpen, Antwerp Area, Belgium), Melda Saglam (Hacettepe University, Ankara, Turkey), Sema Savci (Dokuz Eylul University, İzmir, Turkey), Kathrin Suess (Asklepios Klinik Gauting GmbH, Gauting, Germany), Amanda Thomas (The Royal London Hospital, London, UK), Michel Toussaint (Hospital Inkendaal, Sint-Pieters-Leeuw, Belgium), Naciye Vardar-Yagli (Hacettepe University, Ankara, Turkey), Francois Vermeulen (Geneva University Hospitals, Geneva, Switzerland), Maximilian Zach (University of Graz, Graz, Austria). Julia Bott is acknowledged for fostering the initial idea of creating a harmonised syllabus and curriculum for respiratory physiotherapy. Group 9.2 (Physiotherapy) is acknowledged for their support in the genesis of the project.

\section{Conflict of interest}

T. Troosters has nothing to disclose. N. Tabin is an employee of the European Respiratory Society. D. Langer has nothing to disclose. C. Burtin has nothing to disclose. M. Chatwin has nothing to disclose. E.M. Clini has nothing to disclose. M. Emtner has nothing to disclose. R. Gosselink has nothing to disclose. K. Grant has nothing to disclose. D. Inal-Ince has nothing to disclose. A. Lewko has nothing to disclose. E. Main has nothing to disclose. S. Mitchell was an employee of the European Respiratory Society. A. Niculescu was an employee of the European Respiratory Society between April 2015 and July 2017. B. Oberwaldner has nothing to disclose. F. Pitta has nothing to disclose.

\section{References}

1. World Confederation for Physical Therapy. Entry level physical therapy education programmes. www.wcpt. org/education/Entry-level-physical-therapy-educationprogrammes Date last accessed: April 8, 2019. Date last updated: October 24, 2018.

2. Mitchell S, Pitta F, Troosters T. Standardised education and training for respiratory physiotherapists. Breathe 2013; 9: 171-174.

3. Pitta F, Mitchell S, Chatwin M, et al. A core syllabus for postgraduate training in respiratory physiotherapy. Breathe 2014; 10: 220-228.

4. Twose P, Jones U, Cornell G. Minimum standards of clinical practice for physiotherapists working in critical care settings in United Kingdom: a modified Delphi technique. J Intens Care Soc 2018; 20: 118-131.

5. van Aswegen H, Patman S, Plani N. Developing minimum clinical standards for physiotherapy in South African ICUs: a qualitative study. J Eval Clin Pract 2017; 23: 1258-1265.

6. Skinner EH, Thomas P, Reeve JC, et al. Minimum standards of clinical practice for physiotherapists working in critical care settings in Australia and New Zealand: a modified
Delphi technique. Physiother Theory Pract 2016; 32 : 468-482.

7. World Confederation for Physical Therapy. WCPT guideline for physical therapist professional entry level education. www. wcpt.org/sites/wcpt.org/files/files/Guideline_PTEducation_ complete.pdf Date last accessed: April 8, 2019.

8. Prideaux D. Curriculum design. BMJ 2003; 326: 268-270.

9. Bloom BS, Engelhart MD, Furst EJ, et al. Taxonomy of educational objectives: The classification of educational goals. In: Handbook I: Cognitive domain. New York, David McKay Company, 1956.

10. Miller GE. The assessment of clinical skills/competence/ performance. Acad Med 1990; 65: Suppl, S63-S67.

11. Adams NE. Bloom's taxonomy of cognitive learning objectives. J Med Libr Assoc 2015; 103: 152-153.

12. Royal College of Physicians and Surgeons of Canada. CanMEDS: Better standards, better physicians, better care. www.royalcollege.ca/rcsite/canmeds/canmeds-framework-e Date last accessed: November 15, 2018.

13. Biggs JB. Teaching for quality learning at university. Buckingham, Open University Press/McGraw Hill, 2011. 